\title{
Vaccination debates may obscure access issues
}

\author{
Cite as: CMAJ 2020 August 10;192:E935-6. doi: 10.1503/cmaj.1095888
}

Posted on cmajnews.com on July 24, 2020

T he uptake of a future vaccine against severe acute respiratory syndrome coronavirus 2 (SARS-CoV-2) will depend on more than winning over the "vaccine hesitant." Just as important, but often overlooked in debates about vaccination, are the people who are willing but unable to vaccinate their families.

Recent efforts to boost immunization rates have tended to focus on countering the small but vocal anti-vaccination movement through education campaigns and strengthening immunization policies for school children.

But those opposed to vaccination only account for a fraction of existing gaps in immunization coverage, says Dr. Natasha Crowcroft, inaugural director of the Centre for Vaccine Preventable Diseases at the University of Toronto. In provinces that require the vaccination of public school students, about $2-3 \%$ have an official exemption, mostly for ideological reasons.

Yet, "we see a gap [in vaccination coverage] of roughly $10 \%-15 \%$ that is unaccounted for in some places," says Crowcroft. "Before we do anything else, we need to figure out what is happening in that gap."

For example, $1.7 \%$ of students in Toronto had exemptions in 2018-19, but another $9 \%$ of students were not fully immunized against diphtheria, tetanus and polio, and nearly $5 \%$ had not received the measles, mumps and rubella vaccine.

Dr. Vinita Dubey, associate medical officer of health at Toronto Public Health, says the gap isn't surprising. With more than 300000 student records to review, "you can expect that every year there are going to be a handful of those students who are not up-to-date," she explains.

Even so, it's unclear why Toronto is seeing a "higher proportion of students

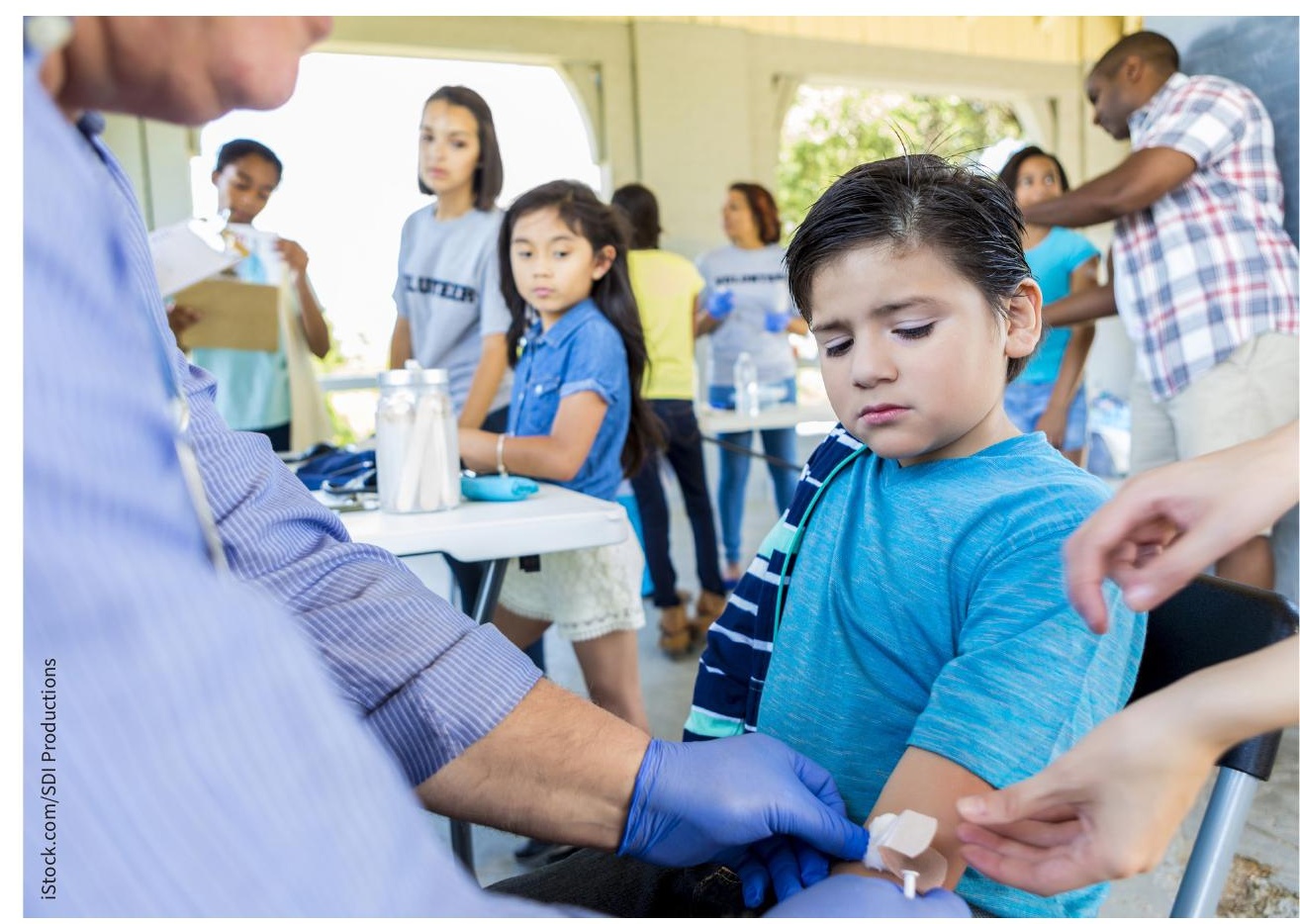

Poor compliance with school immunization policies may have more to do with access issues than anti-vaccination beliefs.

coming up for suspension [because their families haven't sought an exemption]."

An investigation by one Ontario health unit found that poor compliance with school vaccination policies may have more to do with access issues than antivaccination beliefs.

The Simcoe Muskoka District Health Unit found that schools in lower-income neighbourhoods consistently reported higher rates of noncompliance with vaccination policies, with rates as high as $70 \%$ in some areas. But in conversations with surveyors, parents revealed no antivaccination sentiment.

Instead, they cited logistical barriers. "Often low compliance is because of lack of access to a local health care provider or because of challenges with transportation to clinics," says immunization program manager Deanna Thompson. She recalls one parent exclaiming, "You don't understand; I have three jobs and five kids, and I don't have the time!"

Many families in Simcoe Muskoka are transient, making it hard for public health workers to track and maintain their immunization records, Thompson adds. "Often, these are the families that we are missing."

Assumptions about the reasons for low uptake of vaccines may also be muddying the waters. According to British Columbia provincial health officer Dr. Bonnie Henry, there were some parts of the province that "people had always assumed were just anti-vax, but in reality, it turned out that issues were often around access." 
Fraser Health Authority boosted vaccine uptake in these areas by adding more clinics on evenings and weekends for working parents and allowing more drop-in appointments. According to former medical health officer Dr. Shovita Padhi, the effort paid off. "Chilliwack was able to go from a low $60 \%$ coverage rate to over $80 \%$."

Simcoe Muskoka likewise improved vaccination rates in lower-income areas by following up with parents directly and running extra clinics in schools and afterhours. According to Thompson, following these interventions, noncompliance with vaccination policies fell from $71 \%$ to $23 \%$ within the 2018-19 school year.

Toronto Public Health and Peel Public Health have tried similar outreach efforts. But according to Dr. Lawrence Loh, medical officer of health for Peel Region, it's not always straightforward to identify where to direct interventions. In areas where there is limited data, "targeted interventions become a bit of guesswork," he says.

Online and mobile tools for tracking vaccinations, such as the CANImmunize app, are slowly gaining traction in Canada. In Ontario, "the intent is to have people enter their vaccines online" through a provincial portal, says Loh. "But it's going to take some time before these become widely used."

According to Dubey, robust neighbourhood-level data on vaccine coverage and social determinants of health like income would enable public health units to "pinpoint areas with low coverage or high exemptions."

Saskatchewan has analyzed disparities in vaccine uptake amongst low-income neighbourhoods since the mid-2000s. Based on this information, the province has introduced several interventions that have helped to reduce those disparities.

And in the case of COVID-19, Toronto Public Health is now collecting sociodemographic data to understand why infection rates differ in parts of the city, Dubey says.

Health care providers could also play a bigger role in ensuring children are up-todate on their shots, both by administering and reporting vaccinations, even if that's not the reason for their visit. In a similar vein, ensuring access to a routine care provider can also support immunization uptake. "Every clinical encounter should be an opportunity to ensure a child's immunizations are up to date," says Dr. Arlene King, Ontario's former chief medical officer of health.

Sandani Hapuhennedige, Toronto, Ont. 